\title{
Radiation Shielding Properties Comparison of Pb-Based Silicate, Borate, and Phosphate Glass Matrices
}

\author{
Suwimon Ruengsri \\ Chemistry Program, Faculty of Science and Technology, Nakhon Pathom Rajabhat University, Nakhon Pathom 73000, Thailand \\ Correspondence should be addressed to Suwimon Ruengsri; suwimonn@live.com
}

Received 5 December 2013; Accepted 4 January 2014; Published 23 February 2014

Academic Editor: Jakrapong Kaewkhao

Copyright (C) 2014 Suwimon Ruengsri. This is an open access article distributed under the Creative Commons Attribution License, which permits unrestricted use, distribution, and reproduction in any medium, provided the original work is properly cited.

\begin{abstract}
Theoretical calculations of mass attenuation coefficients, partial interactions, atomic cross-section, and effective atomic numbers of $\mathrm{PbO}$-based silicate, borate, and phosphate glass systems have been investigated at $662 \mathrm{keV}$. PbO-based silicate glass has been found with the highest total mass attenuation coefficient and then phosphate and borate glasses, respectively. Compton scattering has been the dominate interaction contributed to the different total attenuation coefficients in each of the glass matrices. The silicate and phosphate glass systems are more appropriate choices as lead-based radiation shielding glass than the borate glass system. Moreover, comparison of results has shown that the glasses possess better shielding properties than standard shielding concretes, suggesting a smaller size requirement in addition to transparency in the visible region.
\end{abstract}

\section{Introduction}

The interaction of high-energy photons with matter is important in radiation medicine and biology, nuclear engineering, and space technology. Glass has double functions of being transparent to visible light and absorbing gamma rays and neutrons, thus, providing a radiation shielding for observers or experimenters. It may also be mentioned that verifications are an interesting option for long-term storage of radioactive waste products [1].

Nowadays, the existing dense silicate flints and their radiation-resistant analogs are characterized by an insufficiently high radiation-optical resistance, a yellowness as a result of a low transmission in the blue and near-UV spectral ranges, high melting temperatures, and a low optical homogeneity due to the corrosive interaction of melts with refractory used for fabricating crucibles and other units of production accessories of a melting facility. This limits the possibility of using radiation-resistant silicate flints for manufacturing radiation-shielding viewing windows for so-called "hot" chambers, medical or industrial radiation facilities, and nuclear and chemical reconnaissance vehicles. Although the existing dense silicate flints have long been manufactured on a commercial scale, it was necessary to design the composition of a new glass that should be transparent over a wider spectral range and have radiation-optical resistance and radiation-shielding properties, at least, no worse than similar characteristics of the existing silicate flints [2].

During the last two decades, borate and phosphate glasses have been investigated extensively, yet there is still a great interest in developing new glasses suited for the demands of both industry and technology. Borate glasses have the promising application for the metal-ceramic seals for their lowing melting temperature and high thermal expansion coefficient matching with that of metals. In such applications, it is found that the glass does not bond directly to the metal but to an oxide that is conventionally formed by a thermal treatment on the metal prior to bonding. The resulting oxide acts as a bonding agent in that it is bonded to the underlying metal and the glass material [3]. In any case, phosphate glasses have low glass transition temperatures, low optical dispersions, and relatively high thermal expansion coefficients $[4,5]$. Furthermore, the poor chemical durability, high hygroscopic, and volatile nature of phosphate glasses prevented them from replacing the conventional glasses in a wide range of technological applications. These properties make them useful candidates for fast ion conducting material, biomedical application, and biocompatible materials, such as 
bone regeneration application [6] and shielding materials [7]. However, the reports of phosphate glass in radiation shielding glass are very limited. Arbuzov and Fyodorov [7] studied optical, spectral, and radiation shielding properties of high lead phosphate glasses.

Good reviews on radiation shielding glass development have been published recently by several authors for several glass matrices, silicate glass [8], borate glass [9-11], and phosphate glass $[2,7]$. In this work, we have calculated the mass attenuation coefficients, the partial interaction, and the effective atomic numbers of silicate, borate, and phosphate glass containing $\mathrm{PbO}$ at $662 \mathrm{keV}$, using WinXCom software. The comparisons of radiation shielding properties between glass matrices are also discussed. The glass formulas in this study are $x \mathrm{PbO}:(100-x) \mathrm{SiO}_{2}, x \mathrm{PbO}:(100-x) \mathrm{B}_{2} \mathrm{O}_{3}$, and $x \mathrm{PbO}:(100-x) \mathrm{P}_{2} \mathrm{O}_{5}$, where $x$ is varied from 30 to $70 \%$ by weight.

\section{Theory and Method}

In this section, we summarize theoretical relations used in the present work. The total probability for interaction $\mu$, called the total linear $(\mu)$ attenuation coefficient, is equal to the sum of the partial probabilities [12]:

$$
\mu=\tau+\sigma+\kappa,
$$

where $\tau, \sigma$, and $\kappa$ are the probability for photoelectric absorption, Compton scattering, and pair production, respectively, and can be derived from the following formula [12]:

$$
\begin{gathered}
\tau\left(\mathrm{cm}^{-1}\right)=a N\left(\frac{Z^{n}}{E_{\gamma}^{m}}\right)[1-f(Z)], \\
\sigma\left(\mathrm{cm}^{-1}\right)=N Z f\left(E_{\gamma}\right), \\
\kappa\left(\mathrm{cm}^{-1}\right)=N Z^{2} f\left(E_{\lambda}, Z\right),
\end{gathered}
$$

in which $a$ is a constant coefficient, independent of $Z$ and $E_{\gamma}$. Parameters $m$ and $n$ are constants with values between 3 and 5 depending on gamma energy. $N$ is atomic density and $Z$ is atomic number. Although the coherent scattering can appear, but it has very tiny influence at high energy. Theoretical values of the mass attenuation coefficients $\left(\mu_{m}\right)$ of mixture or compound have been calculated by WinXCom, based on the mixture rule [13]. Thus

$$
\frac{\mu}{\rho}=\mu_{m}=\sum_{i}^{n} w_{i}\left(\mu_{m}\right)_{i},
$$

where $\left(\mu_{m}\right)_{i}$ is the mass attenuation coefficient for the individual element in each component and $w_{i}$ is the fractional weight of the element in each component. This mixture is valid when the effects of molecular binding and chemical and crystalline environments are negligible. Theoretical values for the mass attenuation coefficient can be found in the tabulation by Hubbell and Seltzer. A lot of manual work can be saved by using suitable software. Berger and Hubbell developed XCOM for calculating mass attenuation coefficients or photon interaction cross-sections for any element, compound, or
TABLE 1: Total mass attenuation coefficients of $\mathrm{PbO}$ containing silicate, borate, and phosphate glass systems at $662 \mathrm{keV}$.

\begin{tabular}{lccc}
\hline $\begin{array}{l}\text { PbO composition } \\
\text { (wt\%) }\end{array}$ & \multicolumn{3}{c}{$\mu_{m}\left(\times 10^{-2} \mathrm{~cm}^{2} / \mathrm{g}\right)$} \\
\hline 30 & Silicate glass & Borate glass & Phosphate glass \\
40 & 8.64 & 8.51 & 8.58 \\
50 & 8.95 & 8.84 & 8.89 \\
60 & 9.25 & 9.16 & 9.21 \\
70 & 9.56 & 9.48 & 9.52 \\
\hline
\end{tabular}

mixture at energy from $1 \mathrm{KeV}$ to $100 \mathrm{GeV}$. Recently, XCOM was transformed to the Windows platform by Gerward et al. [14], called WinXCom.

WinXCom can generate cross-section or attenuation coefficients of element, mixture, and compound on a standard energy grid, spaced approximately logarithmically, on a grid specified by the user, or for a mix of both grids. The program provides total cross-sections and attenuation coefficients as well as partial cross-section for incoherent and coherent scattering, photoelectric absorption, and pair production. For compound, the quantities calculated are partial and total mass attenuation coefficients. Total attenuation coefficients without the contribution from coherent scattering are also given, since they are often used in gammarays transport calculation [15].

\section{Results and Discussion}

The total mass attenuation coefficients of the three $\mathrm{PbO}$ containing glass systems are shown in Table 1. From the table, the total mass attenuation coefficients of PbO-based silicate glass are higher than in phosphate and borate glasses, respectively, showing that photons are more attenuated in silicate glass than the other two glasses. It was found that the total mass attenuation coefficients were increased with increasing $\mathrm{PbO}$ concentration in all glass systems as shown in Table 2. This is due to increasing of interactions via photoelectric absorption in glass samples. The increasing rate and values of photoelectric absorption in all glass systems are comparable and proportional with $\mathrm{PbO}$ content.

The variation of Compton scattering with $\mathrm{PbO}$ concentration in all glass systems is shown in Figure 1; the Compton scattering decreases with increasing $\mathrm{PbO}$ concentration. The decreasing rates of Compton interaction in all glass systems are comparable. The Compton scattering in silicate glass shows the highest in value and then phosphate and borate glass, respectively, reflecting that photons are better scattered in silicate glass at this energy. Moreover, Table 2 shows that in all the glass systems, Compton scattering is a dominate interaction process in this work. These results are explained with total mass attenuation values. While the coherent scattering has only weak effect on the total mass attenuation coefficients for all glass systems, the pair production interaction does not occur because the energy is lower than $1.02 \mathrm{MeV}$. This work has been in good agreement with experimental works by Kirdsiri et al. [16], Singh et al. [11], and Singh et al. [8] in 
TABLE 2: Partial interaction of $\mathrm{PbO}$ containing silicate, borate, and phosphate glass systems at $662 \mathrm{keV}$.

\begin{tabular}{|c|c|c|c|}
\hline $\mathrm{PbO}$ composition (wt\%) & Silicate glass & Borate glass & Phosphate glass \\
\hline \multicolumn{4}{|c|}{ Photoelectric interaction at $662 \mathrm{keV}\left(\times 10^{-2} \mathrm{~cm}^{2} / \mathrm{g}\right)$} \\
\hline 30 & 1.21 & 1.21 & 1.21 \\
\hline 40 & 1.61 & 1.61 & 1.61 \\
\hline 50 & 2.01 & 2.01 & 2.01 \\
\hline 60 & 2.42 & 2.41 & 2.42 \\
\hline 70 & 2.82 & 2.82 & 2.82 \\
\hline \multicolumn{4}{|c|}{ Compton interaction at $662 \mathrm{keV}\left(\times 10^{-2} \mathrm{~cm}^{2} / \mathrm{g}\right)$} \\
\hline 30 & 7.23 & 7.11 & 7.16 \\
\hline 40 & 7.07 & 6.97 & 7.01 \\
\hline 50 & 6.92 & 6.83 & 6.87 \\
\hline 60 & 6.76 & 6.69 & 6.72 \\
\hline 70 & 6.60 & 6.55 & 6.57 \\
\hline \multicolumn{4}{|c|}{ Coherent interaction at $662 \mathrm{keV}\left(\times 10^{-2} \mathrm{~cm}^{2} / \mathrm{g}\right)$} \\
\hline 30 & 0.20 & 0.19 & 0.20 \\
\hline 40 & 0.26 & 0.26 & 0.26 \\
\hline 50 & 0.32 & 0.32 & 0.32 \\
\hline 60 & 0.38 & 0.38 & 0.38 \\
\hline 70 & 0.44 & 0.44 & 0.44 \\
\hline
\end{tabular}

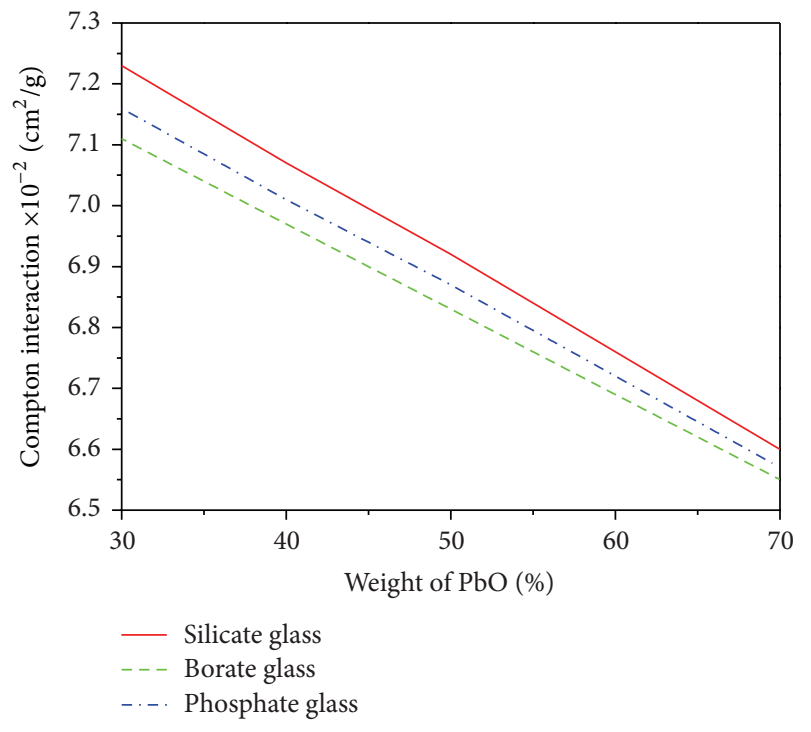

FIGURE 1: The Compton scattering interaction of $\mathrm{PbO}$ containing silicate, borate, and phosphate glass systems at $662 \mathrm{keV}$.

the case of lead borate, bismuth borate, and lead silicate glass systems, respectively. All of partial interaction data are shown in Table 2 along with their $\mathrm{PbO}$ concentrations.

3.1. Cross-Sections and Effective Atomic Numbers. In this section, the total atomic cross-section, $\sigma_{t, a}$, can be expressed as

$$
\sigma_{t, a}=\frac{1}{N_{A}} \sum_{i} f_{i} A_{i} \mu_{m, i}
$$

where $f_{i}$ is the fractional abundance of element $i$ with respect to number of atoms, $A_{i}$ is the atomic weight of element $i$, and $N_{A}$ is the Avogadro constant. Similarly to the total electronic cross-section, $\sigma_{t, e}$, is expressed by the following formula:

$$
\sigma_{t, e}=\frac{1}{N_{A}} \sum_{i} f_{i} \frac{A_{i}}{Z_{i}} \mu_{m, i}
$$

The total atomic and electronic cross-sections are related to the effective atomic number, $Z_{\text {eff }}$, through the following relation:

$$
Z_{\text {eff }}=\frac{\sigma_{t, a}}{\sigma_{t, e}} .
$$

The atomic cross-section and the effective atomic number of the glasses are shown in Table 3. The results show that the effective atomic numbers were increased with increasing of $\mathrm{PbO}$ concentration in all glass systems. It is due to the increasing of photoelectric absorption; as with theoretical approach, the photoelectric absorption depends on atomic number while on the other hand the Compton scattering tends to depend on density [17]. The effective atomic numbers of borate glass are lower than silicate and phosphate glass, respectively; as shown in Figure 2, this is due to lower atomic cross-section as shown in Table 3 . The results are supported by experimental data from Kirdsiri et al. [16]. Figure 3 shows the comparison of mass attenuation coefficients between the glass systems and two concrete systems (ordinary concrete and barite concrete) [10]. It has been observed that all glass systems can obtain better shielding properties than the two concretes for all $\mathrm{PbO}$ concentrations, reflecting that the $\mathrm{PbO}$ containing glasses can be very useful as radiation shielding materials. 


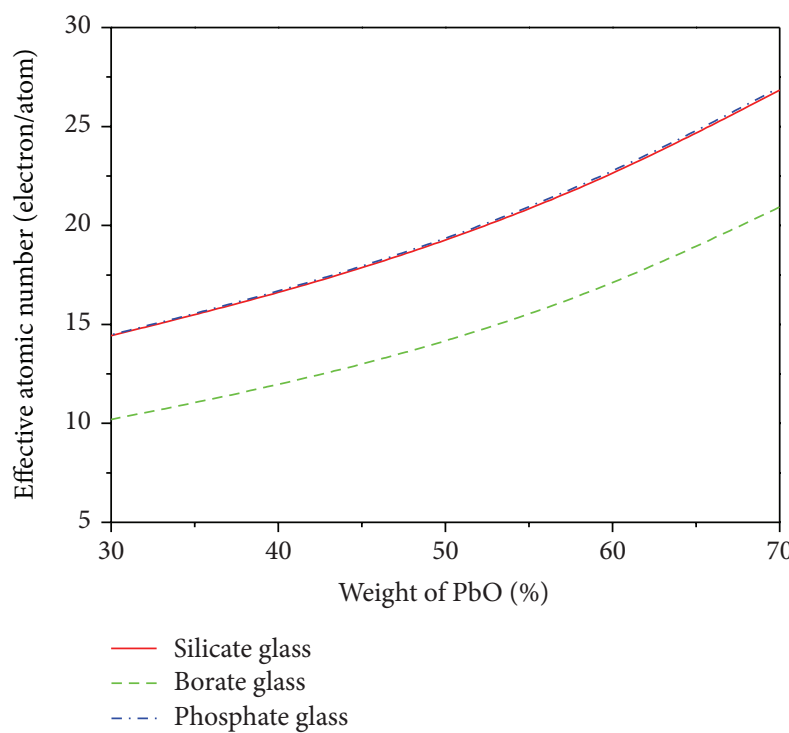

(a)

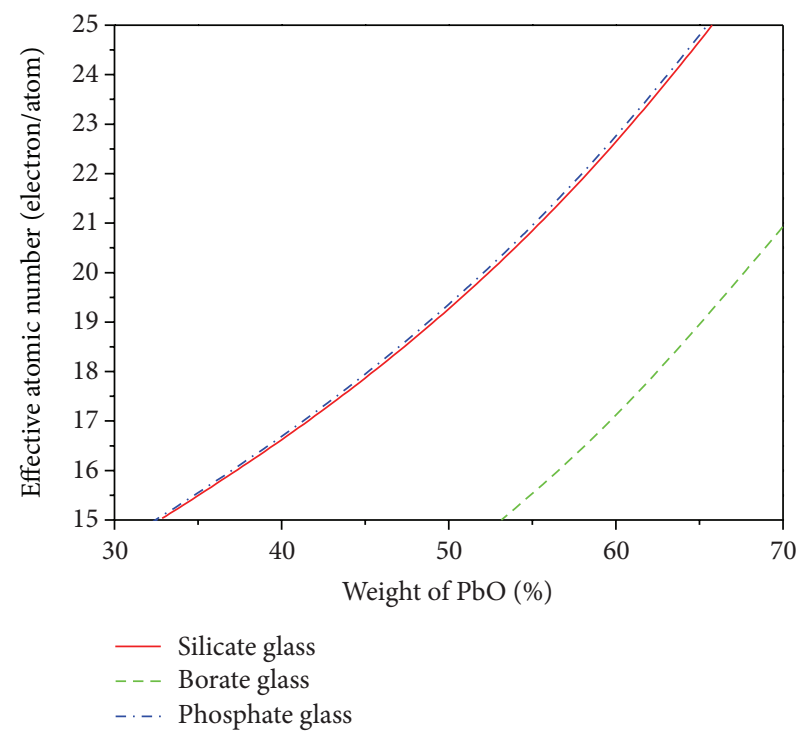

(b)

Figure 2: (a) The effective atomic numbers of $\mathrm{PbO}$ containing silicate, borate, and phosphate glass systems at $662 \mathrm{keV}$; (b) expansion view of (a).

TABLE 3: Total atomic cross-sections and effective atomic numbers of $\mathrm{PbO}$ containing silicate, borate, and phosphate glass system at $662 \mathrm{keV}$.

\begin{tabular}{lccc}
\hline $\begin{array}{l}\text { Composition of } \mathrm{PbO} \\
(\text { wt\% })\end{array}$ & \multicolumn{3}{c}{$\sigma_{t, a}$ (b/atom) } \\
\hline 30 & 3.81 & 2.67 & 3.83 \\
40 & 4.43 & 3.15 & 4.45 \\
50 & 5.22 & 3.77 & 5.25 \\
60 & 6.26 & 4.62 & 6.30 \\
70 & 7.71 & 5.86 & 7.75 \\
\hline Composition of PbO & \multicolumn{4}{c}{$Z_{\text {eff }}$ (electron/atom) } \\
(wt\%) & Silicate glass & Borate glass & Phosphate glass \\
\hline 30 & 14.43 & 10.20 \\
40 & 16.54 & 11.89 & 14.48 \\
50 & 19.15 & 14.06 & 16.61 \\
60 & 22.47 & 16.93 & 22.59 \\
70 & 26.84 & 20.93 & 26.97 \\
\hline
\end{tabular}

Furthermore, the results suggested that silicate and phosphate glass systems are more appropriate than borate glass system as lead-based radiation shielding glass.

\section{Conclusion}

In this work, the mass attenuation coefficients, partial interactions, atomic cross-section, and the effective atomic numbers of silicate, borate, and phosphate glass systems containing $\mathrm{PbO}$ have been investigated. It has been found that silicate and phosphate glass systems are more appropriate than borate glass system in the case of lead-based radiation shielding

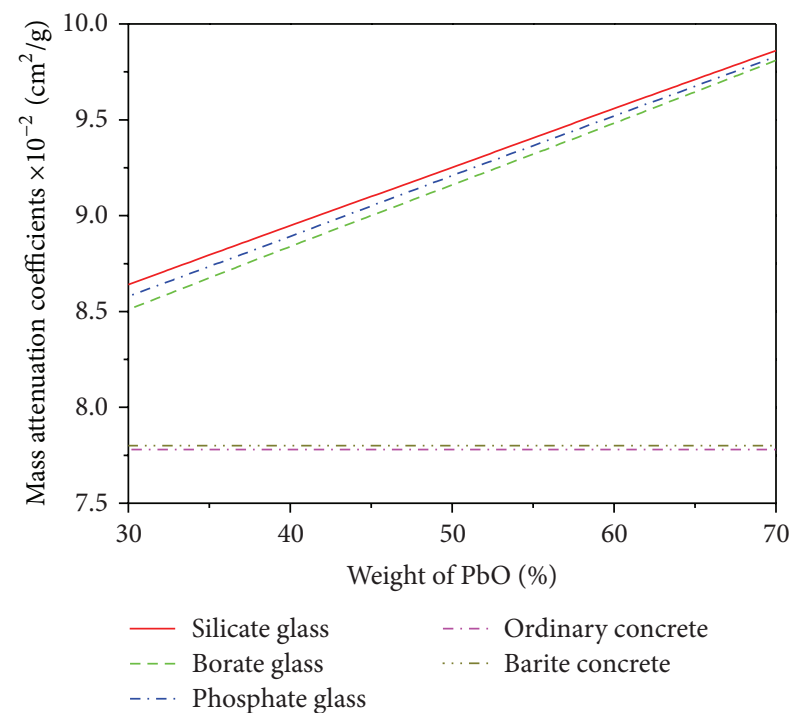

FIgURE 3: The mass attenuation coefficients of $\mathrm{PbO}$ containing silicate, borate, and phosphate glass systems at $662 \mathrm{keV}$ in comparison with two shielding concretes.

glass. However, each glass system may be used depending on the intended application and experimental rechecks which are vital. Our results showed that the glasses are potential candidates for gamma-rays shielding materials. They exhibited with better values of shielding properties in comparison with some standard shielding concretes. This suggested a smaller size requirement in addition to transparency in the visible region.

Further investigations on the photon absorption in the glass materials are in progress, especially on other theoretical 
treatments such as X-ray form factor, attenuation, and scattering table (FFAST) $[18,19]$ to establish uncertainties estimation for better reliability of the results.

\section{Conflict of Interests}

The author declares that there is no conflict of interests regarding the publication of this paper.

\section{Acknowledgment}

The author would like to thank Nakhon Pathom Rajabhat University (NPRU) for partially supporting this paper.

\section{References}

[1] S. R. Manohara, S. M. Hanagodimath, and L. Gerward, "Photon interaction and energy absorption in glass: a transparent gamma ray shield," Journal of Nuclear Materials, vol. 393, no. 3, pp. 465-472, 2009.

[2] V. I. Arbuzov, N. Z. Andreeva, N. A. Leko, S. I. Nikitina, N. F. Orlov, and Y. K. Fedorov, "Optical, spectral, and radiationshielding properties of high-lead phosphate glasses," Glass Physics and Chemistry, vol. 31, no. 5, pp. 583-590, 2005.

[3] D. Zhu, X. Lou, F. Luo, L. Xiong, and W. Zhou, "Electronic structure and physical properties of hcp $\mathrm{Ti}_{3} \mathrm{Al}$ type alloys," Transactions of Nonferrous Metals Society of China, vol. 17, no. 4, pp. 766-771, 2007.

[4] G. L. Flower, G. S. Baskaran, M. S. Reddy, and N. Veeraiah, "The structural investigations of $\mathrm{PbO}-\mathrm{P}_{2} \mathrm{O}_{5}-\mathrm{Sb}_{2} \mathrm{O}_{3}$ glasses with $\mathrm{MoO}_{3}$ as additive by means of dielectric, spectroscopic and magnetic studies," Physica B, vol. 393, no. 1-2, pp. 61-72, 2007.

[5] H. Doweidar, Y. M. Moustafa, K. El-Egili, and I. Abbas, "Infrared spectra of $\mathrm{Fe}_{2} \mathrm{O}_{3}-\mathrm{PbO}-\mathrm{P}_{2} \mathrm{O}_{5}$ glasses," Vibrational Spectroscopy, vol. 37, no. 1, pp. 91-96, 2005.

[6] L. D. Burling, Novel phosphate glasses for bone. Regeneration applications [Ph.D. thesis], University of Nottingham, 2005.

[7] V. I. Arbuzov and Y. K. Fyodorov, "Spectral, radiation-optical and shielding properties of phosphate glasses with high lead content," Advanced Materials Research, vol. 39-40, pp. 213-218, 2008.

[8] K. J. Singh, N. Singh, R. S. Kaundal, and K. Singh, "Gammaray shielding and structural properties of $\mathrm{PbO}-\mathrm{SiO}_{2}$ glasses," Nuclear Instruments and Methods in Physics Research B, vol. 266, no. 6, pp. 944-948, 2008.

[9] N. Singh, K. J. Singh, K. Singh, and H. Singh, "Gamma-ray attenuation studies of $\mathrm{PbO}-\mathrm{BaO}-\mathrm{B}_{2} \mathrm{O}_{3}$ glass system," Radiation Measurements, vol. 41, no. 1, pp. 84-88, 2006.

[10] N. Singh, K. J. Singh, K. Singh, and H. Singh, "Comparative study of lead borate and bismuth lead borate glass systems as gamma-radiation shielding materials," Nuclear Instruments and Methods in Physics Research B, vol. 225, no. 3, pp. 305-309, 2004.

[11] K. Singh, H. Singh, V. Sharma et al., "Gamma-ray attenuation coefficients in bismuth borate glasses," Nuclear Instruments and Methods in Physics Research B, vol. 194, no. 1, pp. 1-6, 2002.

[12] M. Jalali and A. Mohammadi, "Gamma ray attenuation coefficient measurement for neutron-absorbent materials," Radiation Physics and Chemistry, vol. 77, no. 5, pp. 523-527, 2008.

[13] D. F. Jackson and D. J. Hawkes, "X-ray attenuation coefficients of elements and mixtures," Physics Reports, vol. 70, no. 3, pp. 169-233, 1981.
[14] L. Gerward, N. Guilbert, K. Bjorn Jensen, and H. Levring, "X-ray absorption in matter. Reengineering XCOM," Radiation Physics and Chemistry, vol. 60, no. 1-2, pp. 23-24, 2001.

[15] L. Gerward, N. Guilbert, K. B. Jensen, and H. Levring, "WinXCom-a program for calculating X-ray attenuation coefficients," Radiation Physics and Chemistry, vol. 71, no. 3-4, pp. 653-654, 2004.

[16] K. Kirdsiri, J. Kaewkhaob, A. Pokaipisitc, W. Chewpraditkula, and P. Limsuwana, "Gamma-rays shielding properties of $x \mathrm{PbO}:(100-x) \mathrm{B}_{2} \mathrm{O}_{3}$ glasses system at $662 \mathrm{keV}$," Annals of Nuclear Energy, vol. 36, no. 9, pp. 1360-1365, 2009.

[17] N. Tsoulfaniidis, Measurement and Detection of Radiation, pp. 144-147, Hemisphere Publishing, Washington, DC, USA; McGraw-Hill, New York, NY, USA, 1983.

[18] C. T. Chantler, "Theoretical form factor, attenuation, and scattering tabulation for $Z=1-92$ from $E=1-10 \mathrm{eV}$ to $E=0.4-1.0 \mathrm{MeV}$," Journal of Physical and Chemical Reference Data, vol. 24, no. 1, p. 71, 1995.

[19] C. T. Chantler, "Detailed tabulation of atomic form factors, photoelectric absorption and scattering cross section, and mass attenuation coefficients in the vicinity of absorption edges in the soft X-ray $(Z=30-36, Z=60-89, E=$ $0.1-10 \mathrm{keV}$ )—addressing convergence issues of earlier work," Journal of Physical and Chemical Reference Data, vol. 29, no. 4, p. $597,2000$. 


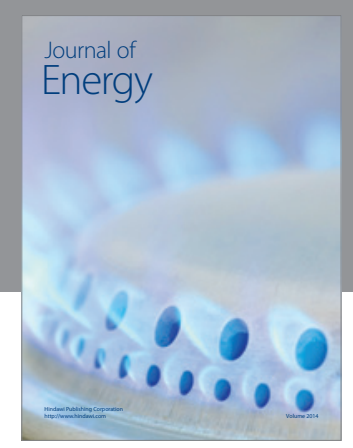

Journal of

Industrial Engineering
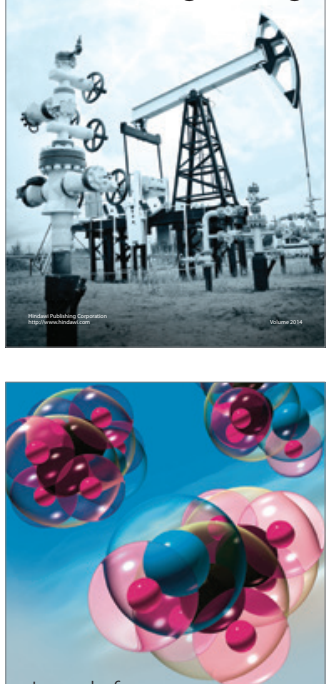

Fuels
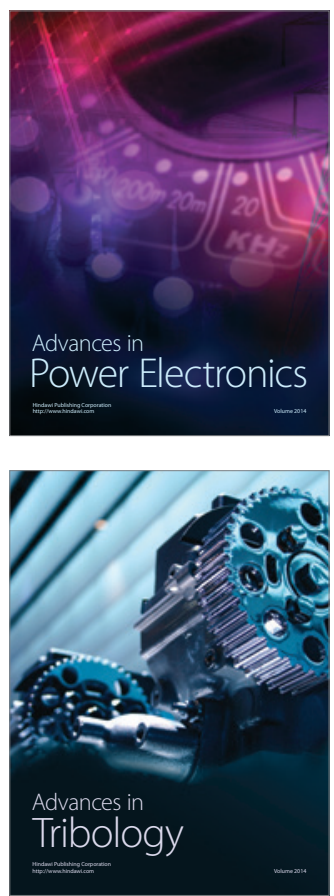

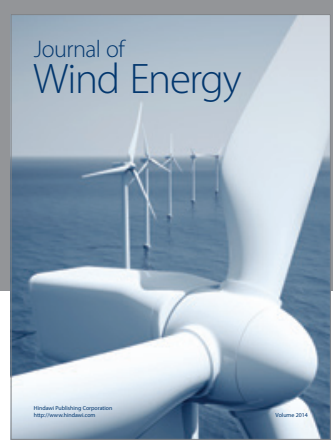

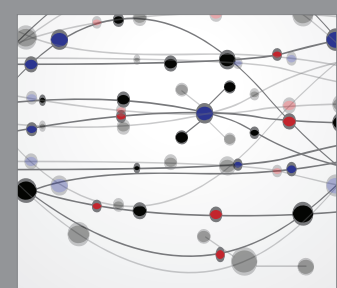

The Scientific World Journal

Submit your manuscripts at http://www.hindawi.com

Journal of

Structures
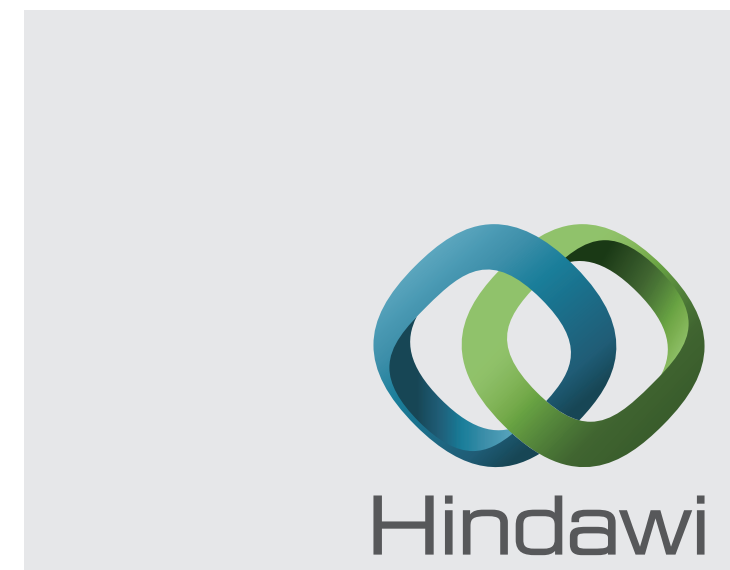

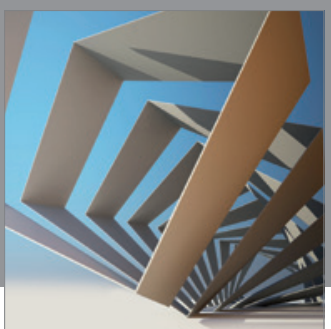

Rotating

Machinery
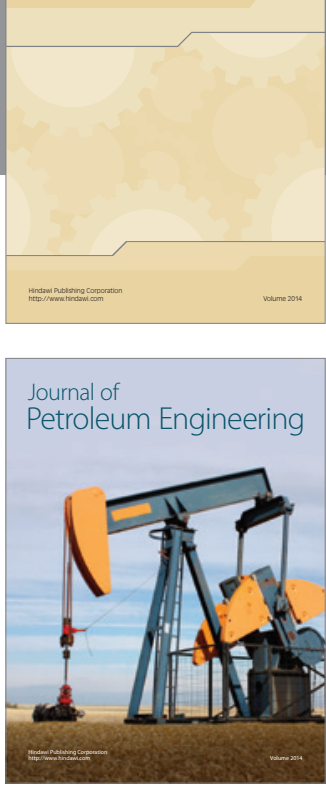

Journal of

Solar Energy
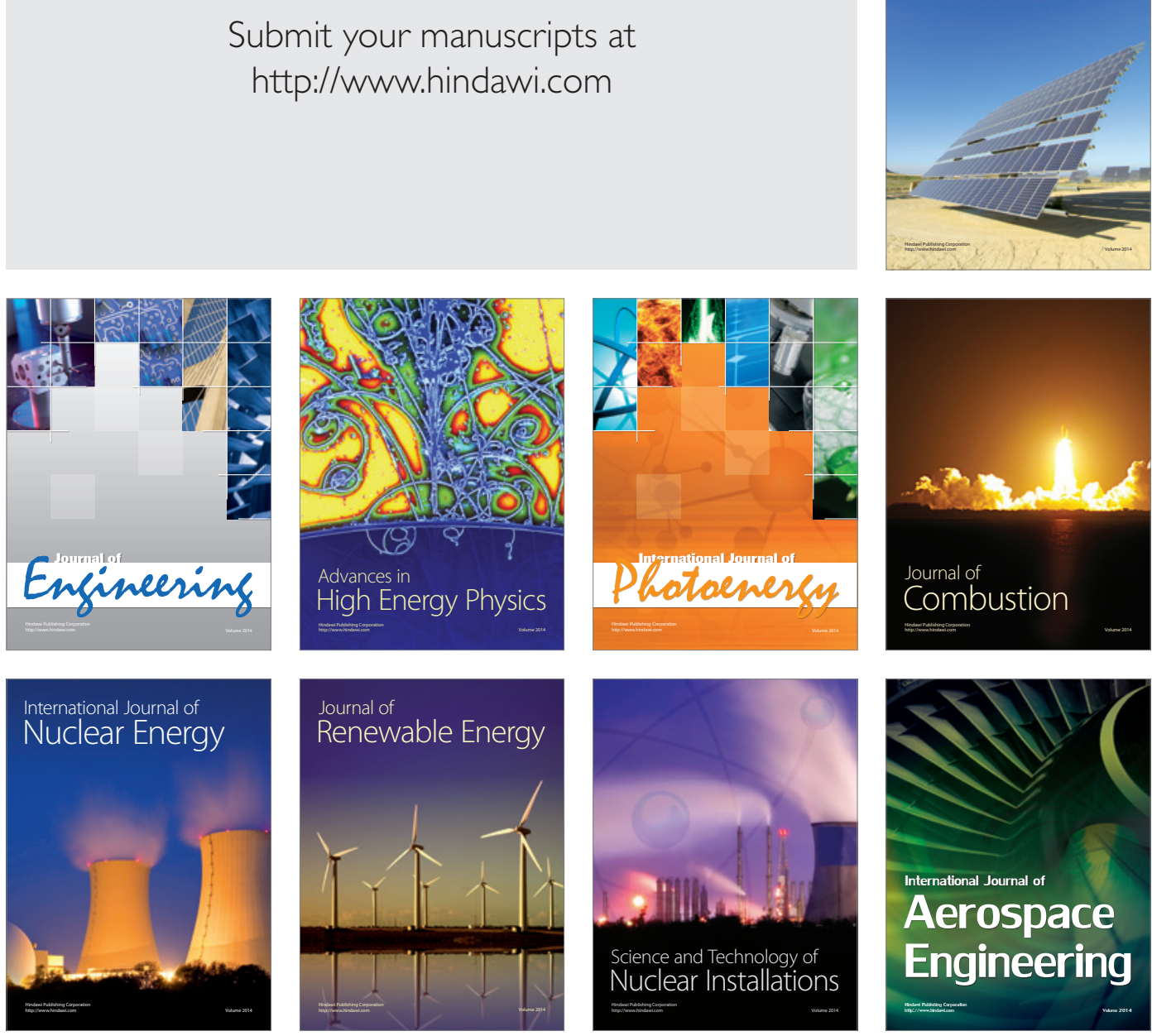